\title{
FORMAÇÃO CONTINUADA DE PROFESSORES DA E NA EDUCAÇÃO SUPERIOR ${ }^{1}$
}

\author{
Continuing education for professors from and in higher education
}

\author{
Eliana de Freitas Soares ${ }^{2}$ \\ Dânia Barro ${ }^{3}$ \\ Cíntia C. Maciel Neves ${ }^{4}$
}

RESUMO: Trazer reflexões sobre o trabalho a ser desenvolvido na Educação Superior é algo que se encontra com alguma frequência, principalmente quando se trata de pesquisas realizadas no campo da Educação. Mas abordar especificamente a formação continuada nesse meio, nem sempre é um tema que fica evidente nas discussões acadêmicas no âmbito da pesquisa, pois aparece com mais incidência no campo da extensão. Com base nisso o objetivo desse artigo é apresentar o que tem sido discutido no âmbito das pesquisas realizadas no Brasil no que diz respeito à formação continuada do professor na Educação Superior. A metodologia teve abordagem qualitativa com objetivo exploratório. Os resultados apontam para a importância da formação continuada para os professores da Educação Superior, contudo há necessidade de as Instituições de Educação Superior (IES), junto com seus professores, desenvolverem ações para essa finalidade que muitas vezes não têm sido realizadas de forma que atenda aos anseios dos envolvidos.

Palavras-chave: Educação Superior. Professores. Formação continuada.

ABSTRACT: Reflections on work developed in Higher Education are frequently found in the literature, mainly when dealing with research carried out in the field of Education. However, studies specifically addressing continuing education in this field are not always seen in academic discussions in the scope of research, since they appear more commonly in the area of extension. As such, the goal of this article is to present what has been discussed in the scope of research carried out in Brazil with respect to continuing education for professors in Higher Education. The methodology was qualitative in nature with an exploratory objective. The results indicate the importance of

\footnotetext{
${ }^{1}$ O presente trabalho foi realizado com apoio da Coordenação de Aperfeiçoamento de Pessoal de Nível Superior Brasil (CAPES) - Código de Financiamento 001.

${ }^{2}$ Mestre em Educação. Professora lotada no Departamento de Métodos e Técnicas Educacionais - Universidade Estadual de Montes Claros (Unimontes). E-mail: edfsoares@gmail.com.

${ }^{3}$ Doutora em Educação. Professora do Centro Universitário IDEAU. E-mail: dania@ideau.com.br.

${ }^{4}$ Licenciada em Pedagogia. E-mail: cintianmaciel@gmail.com.
} 
continuing education for professors in Higher Education, though Higher Education Institutions (HEI), together with its professors, need to develop actions for this purpose, which have often not been done in a way that meets the needs of those involved.

Keywords: Higher Education. Professors. Continuing education.

INTRODUÇÃO

O que é ser professor? Perguntar para qualquer pessoa o que faz o professor é fácil. Dicionários, pesquisas, estudos especializados irão responder: o professor é quem ensina. Essa é a base dessa profissão. Mas perguntar a um professor o que é ser professor, a resposta que se encontrará muitas vezes abrangerá muitos outros aspectos para além de ensinar. E ensinar o que? Habilidades, competências, e que tantas outras coisas... E no período que a humanidade vive em pleno século XXI com a pandemia do Covid-19 pode se encontrar muitas outras razões para o ser professor.

Para Freire (2015) professor é aquele que em diálogo com seus educandos se educa e também, é aquele que possui comprometimento com seu trabalho, que jamais trabalha sem embasamento teórico, mas que busca refletir com criticidade suas práticas, segundo suas palavras "a responsabilidade ética, política e profissional do ensinante lhe coloca o dever de se preparar, capacitar." (FREIRE, 1995, p. 28).

Dessa forma, pode-se entender que o professor, segundo Freire (1995), é quem está sempre em análise na e com a sua prática em qualquer grau de ensino e acima de tudo, é quem reconhece as dificuldades de exercer sua profissão, além de buscar melhorá-la. Essa concepção faz parte do ser professor. Também na legislação brasileira há algumas diretrizes para quem deseja seguir nessa profissão.

Uma das mais importantes leis é a Lei de Diretrizes e Bases da Educação Nacional (LDBEN) nº 9394 de 1996, que no seu art. 62 estabelece que a formação do professor da Educação Básica "far-se-á em nível superior, em curso de licenciatura plena, admitida, como formação mínima para o exercício do magistério na educação infantil e nos cinco primeiros anos do ensino fundamental, a oferecida em nível médio, na modalidade normal.” (BRASIL, 1996, p. 43). Nesta mesma lei, logo a seguir também orienta sobre a formação continuada e a capacitação dos professores de magistério que devem ser de responsabilidade colaborativa da União, Distrito Federal, Estados e Municípios. (BRASIL, 1996).

Quanto a formação do professor da Educação Superior, assim a lei instrui em seu art. 66, “a preparação para o exercício do magistério superior far-se-á em nível de pós-graduação, prioritariamente em programas de mestrado e doutorado.” (BRASIL, 1996, p. 44). Mas um dos 
grandes problemas que a LDBEN 9394/96 não previu é que nem todos os cursos de mestrado e doutorado têm disciplinas voltadas à docência, disciplinas associadas às práticas que norteiam os processos de ensino e de aprendizagem no dia a dia da sala de aula do futuro professor da Educação Superior.

Uma das críticas é que o corpo docente universitário consiste de profissionais formados em diferentes áreas de conhecimento e que, mesmo tendo passado por uma formação de mestrado e doutorado, pouco estudaram sobre ser professor. De acordo com Gil (2007), diferentemente dos professores da Educação Básica, não tiveram em sua formação inicial o estudo de disciplinas como Psicologia da Educação, Didática e Prática de Ensino, ou seja, disciplinas que têm como objetivo capacitar o profissional para o desempenho da atividade docente como didática e processos de ensino e de aprendizagem.

Tendo em vista que os estudantes da Educação Superior são adultos, acreditou-se por muito tempo que a principal necessidade do professor era o domínio do conhecimento específico a ser lecionado. Estudantes mais adultos, com interesse profissional já traçado, estariam suficientemente motivados e dedicados à aprendizagem. Essa situação foi mudando à medida que a universidade passou a receber mais estudantes, bem como um novo perfil estudantil e cursos variados, exigindo qualidade de ensino, levando a uma reflexão sobre a necessidade de capacitar pedagogicamente os docentes de nível superior (GIL, 2007).

Sobre esse último aspecto a pesquisa de Felicetti e Santos (2019) aponta que como há um aumento de ingressos na Educação Superior nos últimos anos, também há uma mudança de perfil de estudantes. Por serem de universos heterogêneos há uma grande diversidade psicossocial e socioeconômica. Alunos com diferentes deficiências, diferentes raça e cor, estudantes de primeira geração que não tiveram em seu núcleo familiar nenhum membro que cursou a Educação Superior anteriormente, estão mais presentes nas instituições e demanda que as mesmas planejem estratégias que permitam a equidade na sua permanência.

O que implica, principalmente para os alunos com diferentes deficiências na Educação Superior, por "em cena um novo fazer na universidade, o qual exige saberes necessários para a promoção da aprendizagem desse novo alunado. Esse perfil estudantil requer que a ele sejam consideradas as singularidades atinentes a sua aprendizagem, logo, profissionais capacitados são exigidos.” (FELICETTI; SANTOS, 2019, p. 216).

Assim, pode-se afirmar que o trabalho docente é uma atividade complexa, e a formação de profissionais das diversas áreas para a docência também o é. Contudo, de acordo com Morosini (2014) e Leite (1999), o professor é fundamental para a melhora dos indicadores de qualidade da Educação Superior. Partindo dessa reflexão, torna-se urgente falar de formação continuada para os 
professores que atuam em Instituições de Educação Superior, na intenção de complementar e preencher lacunas importantes para a constituição docente.

Com base nestas reflexões iniciais, o problema que suscitou este estudo foi como a formação continuada de professores da Educação Superior tem sido abordada nas pesquisas realizadas no Brasil e como objetivos: apresentar o que tem sido discutido no âmbito das pesquisas realizadas no Brasil no que diz respeito à formação continuada do professor na Educação Superior e explicitar a importância da formação continuada de professores na Educação Superior. A partir da literatura buscou-se identificar como o professor da Educação Superior é constituído e também, demonstrar a importância da formação continuada para o professor da Educação Superior. A metodologia adotada teve abordagem qualitativa com objetivo exploratório.

\section{O PROFESSOR DA EDUCAÇÃO SUPERIOR}

O professor da Educação Superior foi por muito tempo visto como alguém que ao saber fazer, automaticamente saberia ensinar. Associando esse pensamento ao fato de que a universidade era privilégio de poucos, os quais precisavam saber puramente o conteúdo técnico, teve-se por um longo período, a docência na Educação Superior como uma simples atividade (MASETTO, 2008).

Com o crescimento da universidade, a docência passou a ser vista como uma profissão e para tal haveria a necessidade de se estabelecer requisitos que caracterizassem a mesma. De acordo com Gil (2007), o professor da Educação Superior é constituído a partir de requisitos legais, pessoais e técnicos.

Nos requisitos legais, como citado anteriormente, a formação do professor para a Educação Superior é a nível de mestrado e doutorado. O Instrumento de Avaliação de cursos de Graduação, elaborado pelo Sistema Nacional de Avaliação da Educação Superior (SINAES), aponta como ideal um corpo docente com formação stricto sensu maior ou igual a 30\% do total de professores, com experiência profissional em sua área de formação de 2 a 3 anos e experiência no magistério superior de 3 anos. Ainda estabelece uma produção científica, cultural, artística ou tecnológica de pelo menos 3 trabalhos nos últimos 3 anos (BRASIL, 2016).

Neste aspecto é possível fazer uma crítica já que em nenhum momento da avaliação dos SINAIS é colocado como critério a atuação do docente, enquanto docente, ou seja, quais são as habilidades e competências desse profissional para formar outros profissionais. Em outras palavras, como, didaticamente, esse docente está preparado para desempenhar a função de professor em sala de aula? 
O segundo requisito seria os pessoais, ou seja, que aptidões, experiência, iniciativa, criatividade entre outros, a que pessoa teria para ser docente na Educação Superior. De acordo com Gil (2007) a profissão professor é uma daquelas profissões em que a caracterização dessas habilidades seria além de difícil, muito vulnerável, visto da complexidade da mesma. E para complementar essa ideia, a complexidade também está "nos valores da profissionalização e profissionalidade docente" que Contreras (2002) discute trazendo elementos para se pensar a "autonomia, responsabilidade e capacitação" que estão associados e precisam ser indiscutíveis ao profissional da docência. No que diz respeito ao aspecto pessoal também está implícito a obrigação moral que tem uma relação direta ao aspecto emocional que o processo ensino e o de aprendizagem envolve.

Há outros aspectos, também complexos à profissão docente. Entre eles os físicos e fisiológicos, como voz, resistência à fadiga entre outros, psicotemperamentais, incluindo autoconfiança, paciência, estabilidade emocional, disciplina; e intelectuais, memória, inteligência abstrata e verbal, associação, coordenação, entre outras. Também se encontra neste requisito, a necessidade de compreensão de que em muitas situações, pode-se encontrar profissionais que não atendam a essas características todas, mas conseguem realizar a profissão com maestria, firmados na vocação de ser professor (GIL, 2007).

Para o terceiro requisito que são os chamados técnicos, pode-se citar a importância do domínio de conteúdo, para que o professor possa ressaltar os seus aspectos fundamentais e esclarecer sobre suas aplicações práticas. Um exemplo seria quando se trabalha com conteúdos práticos onde o professor deve ter experiência para poder realizá-los com segurança. Reside junto a esse aspecto as questões culturais do professor, ou seja, o conhecimento do mundo ao seu redor para poder integrar sua disciplina neste contexto. Além da articulação entre o seu conteúdo com os demais, sendo este um conhecimento importante que apresente ao aluno (GIL, 2007). O autor supracitado, ainda sobre requisitos técnicos, apresenta conhecimentos e habilidades pedagógicas como de fundamental importância. Sendo destacados: conhecimento e estrutura da Educação Superior, planejamento de ensino, psicologia da aprendizagem, métodos de ensino e técnicas de avaliação.

Os, segundo e terceiro requisitos, contemplam o olhar para o professor enquanto profissional, e talvez se pensar neles à luz do significado de competências necessárias para o trabalho, consiga-se definir melhor o professor da Educação Superior. Competência, segundo Perrenoud (1999), é a capacidade de enfrentar uma situação, mobilizando de forma correta, rápida, pertinente e criativa, múltiplos recursos cognitivos: saberes, capacidades, microcompetências, informações, valores, atitudes, esquemas de percepção, de avaliação e de raciocínio. 
Tendo em vista essa definição de competência, Masetto (2008) traz algumas dessas competências básicas para a docência na Educação Superior:

- Domínio dos conhecimentos básicos de determinada área, ou seja, saber sobre o que vai ensinar. É preciso agregar a esse conhecimento, vivências práticas e estudos de pesquisa.

- Domínio pedagógico: a área mais carente dos professores atualmente. Referese à preparação pedagógica; concepção e gestão do currículo; as relações professoraluno e aluno-aluno; o domínio da tecnologia educacional; a concepção do processo avaliativo, o feedback de suas atividades, o planejamento como atividade educacional e política.

- Dimensão política: trata-se de considerar o professor como ser cidadão que é, com sua cultura, sua visão de mundo, de sociedade, e de aproveitar-se dessa condição para dialogar com outros cidadãos (alunos). E assim, numa perspectiva bem realista, trabalhar o seu conteúdo relacionado a condição social e de mercado que cada profissão exige.

Já Tardif (2015) traz o conceito de "saber", numa dimensão que abarca conhecimentos, competências, habilidades e as atitudes. Ou seja, um conjunto de fatores importantes de serem conhecidos e adquiridos pelo docente. Enfatiza que esses saberes carregam marcas de ser humano, pelo fato de que seu objeto de trabalho são seres humanos, e que estes possuem particularidades individuais apesar de pertencerem a um grupo, e como tal precisam ser olhados individualmente. O professor precisa de muita sensibilidade e discernimento para identificar cada um de seus alunos e a forma de encantá-los com o conteúdo, de despertar neles a aprendizagem.

Além das competências também é importante conhecer como a identidade do professor é constituída. Principalmente para aqueles que entraram na docência tendo como critério o conhecimento técnico adquirido. Pimenta (2002) afirma que a identidade é um processo construído pelo sujeito em um determinado contexto histórico. Professor é uma profissão que passa por significado social, cultural.

Para a construção da identidade docente, a autora sintetiza os saberes da docência em três áreas: a experiência, o conhecimento e os saberes pedagógicos. A experiência é o que diz respeito sobre o que é ser professor na visão da pessoa que está entrando na profissão docente. Quais os ensinamentos, posturas, valores, imagem que os professores que passaram pela sua vida deixaram em sua história. Assim precisa "ver-se como professor. Isto é, de construir a sua identidade de professor". (PIMENTA, 2002, p. 20).

O conhecimento está relacionado a conhecer, ou seja, "significa estar consciente do poder do conhecimento para a produção da vida material, social e existencial da humanidade" (PIMENTA, 2002, p. 22). Não é só trazer a informação, apresentá-la para os alunos em sala de 
aula, mas ser o mediador entre a informação e o conhecimento que é uma operação a mais que o aluno precisa realizar.

O terceiro saber diz respeito aos saberes pedagógicos. Sobre essa ideia a autora esclarece,

O futuro profissional não pode constituir seu saber-fazer senão a partir de seu próprio fazer. Não é senão sobre essa base que o saber, enquanto elaboração teórica, se constitui. Frequentando os cursos de formação, os futuros professores poderão adquirir saberes sobre a educação e sobre a pedagogia, mas não estarão aptos a falar em saberes pedagógicos. (PIMENTA, 2002, p. 26).

Nessa parte Pimenta (2002, p. 26) se fundamenta em Houssaye (1995) ao afirmar "a especificidade da formação pedagógica, tanto a inicial como a contínua, não é refletir sobre o que se vai fažr, nem sobre o que se deve fazer, mas sobre o que se faそ". São contribuições que ajudam a compreender a complexidade do ser professor. E principalmente que é necessária uma formação que não seja estanque, pois é um processo.

Pimenta e Anastasiou (2005) afirmam que os pesquisadores de diferentes áreas científicas adentram à Educação Superior como consequência de suas atividades, e adoram naturalmente o ofício de professor, sem inteirar-se sobre a importância e o cuidado dessa profissão. E é exatamente neste ponto que entra a formação continuada, objeto desse estudo, que possibilita a discussão sobre aspectos da constituição docente, que oportuniza ao docente discutir e refletir sobre a sala de aula, seu papel, o significado de aprender e ensinar, o encaminhamento metodológico, planejamento entre outros, ou seja, os saberes pedagógicos.

\section{METODOLOGIA}

Este estudo caracteriza-se por uma pesquisa de cunho qualitativo com objetivo exploratório que se deu por pesquisa tipo revisão da literatura. Segundo Diehl e Tatim (2004), a pesquisa qualitativa é usada para descrever a complexidade de determinado problema e a interação de certas variáveis. Já a pesquisa exploratória, permite uma maior familiaridade com o problema, e na maioria das vezes acontece por meio de pesquisa bibliográfica, ou seja, levantamento de dados a partir de material já elaborado como livros, artigos científicos entre outros documentos.

Realizou-se uma busca no banco de dados da Biblioteca Digital Brasileira de Teses e Dissertações (BDTD), utilizando as palavras-chave "Formação Continuada" e "Educação Superior", no período entre 02 de julho e 27 de agosto de 2020. Foram encontrados 101 trabalhos com as respectivas palavras-chave, publicados entre 2003 e 2020, cujos resumos foram analisados para identificar àqueles que tratavam exclusivamente da Formação Continuada para Educação 
Superior. Um aspecto que foi limitador é que em alguns trabalhos listados o resumo não deixava claro o tipo de pesquisa realizada, a metodologia adotada ou mesmo os resultados encontrados. Em alguns as palavras-chave não apareceram.

Mas dos 101 trabalhos destaca-se que foram identificadas áreas da educação, comunicação social, engenharia elétrica e computação, informática na educação, serviço social, matemática, estudos da tradução, gestão estratégica para as IES, desenvolvimento e políticas públicas, ensino em ciências da saúde, educação agrária, políticas públicas e gestão da Educação Superior, gestão de práticas educativas, letras estrangeiras modernas, contabilidade, planejamento e análise de políticas públicas, processo de desenvolvimento humano e saúde, gestão e avaliação da educação, engenharia de produção. A educação teve predominância com 80 trabalhos.

Da análise dos resumos desses trabalhos, constatou-se que 27 tratavam da Formação Continuada para Educação Superior, sendo 15 dissertações e 12 teses, mas que trouxeram nas palavras-chave o descritor formação continuada foram 10, os quais foram escolhidos para leitura e análise na íntegra e corresponderam a seis dissertações e quatro teses. Quanto aos programas de Pós-Graduação a que pertencem, nove são da Educação e um de Planejamento e Análise de Políticas Públicas. Dois trabalhos foram defendidos em 2012 e dois em 2019, um trabalho em cada um dos seguintes anos: 2017, 2016, 2014, 2013, 2010 e 2007. Quatro trabalhos foram defendidos em universidades estaduais, cinco em universidades federais e um em universidade comunitária. Para melhor visualização dos trabalhos, segue o Quadro 1 om as informações gerais.

Quadro 1 - Visão Geral dos Trabalhos Analisados na Íntegra

\begin{tabular}{|c|c|c|c|c|c|}
\hline $\begin{array}{l}\text { Nome do } \\
\text { Pesquisad } \\
\quad \text { or }\end{array}$ & Instituição & Programa & Título & Ano & Tipo \\
\hline $\begin{array}{l}\text { Claudio } \\
\text { Damaceno } \\
\text { Paz }\end{array}$ & $\begin{array}{l}\text { Universida } \\
\text { de do Sul de } \\
\text { Santa } \\
\text { Catarina }\end{array}$ & $\begin{array}{l}\text { Pós- } \\
\text { Graduação em } \\
\text { Educação }\end{array}$ & $\begin{array}{l}\text { O Desafio da Formação de } \\
\text { Professores para a Educação } \\
\text { Superior: o programa de } \\
\text { profissionalização pedagógica } \\
\text { Continuada dos professores da } \\
\text { Unisul }(2004-2009) \text {. }\end{array}$ & 2010 & $\mathrm{D}$ \\
\hline $\begin{array}{l}\text { Fernanda de } \\
\text { Melo } \\
\text { Blanco }\end{array}$ & $\begin{array}{l}\text { Universida } \\
\text { de Estadual } \\
\text { Paulista }\end{array}$ & $\begin{array}{l}\text { Programa de } \\
\text { Pós- } \\
\text { Graduação em }\end{array}$ & $\begin{array}{l}\text { Saberes da Docência: um estudo } \\
\text { sobre a formação dos } \\
\text { professores de História }\end{array}$ & 2017 & $\mathrm{D}$ \\
\hline
\end{tabular}




\begin{tabular}{|c|c|c|c|c|c|}
\hline & $\begin{array}{l}\text { "Júlio de } \\
\text { Mesquita } \\
\text { Filho" }\end{array}$ & $\begin{array}{l}\text { Planejamento } \\
\text { e Análise de } \\
\text { Políticas } \\
\text { Públicas }\end{array}$ & & & \\
\hline $\begin{array}{l}\text { Gabrielle } \\
\text { Barbosa de } \\
\text { Sousa }\end{array}$ & $\begin{array}{l}\text { Universida } \\
\text { de Federal } \\
\text { de } \\
\text { Pernambuc } \\
\text { o }\end{array}$ & $\begin{array}{l}\text { Programa de } \\
\text { Pós- } \\
\text { Graduação do } \\
\text { Centro de } \\
\text { Educação }\end{array}$ & $\begin{array}{l}\text { Formação Continuada de } \\
\text { Professores do Ensino Superior: } \\
\text { composição organizativa da } \\
\text { identidade docente }\end{array}$ & 2013 & $\mathrm{D}$ \\
\hline $\begin{array}{l}\text { Judilma } \\
\text { Aline } \\
\text { Oliveira } \\
\text { Silva }\end{array}$ & $\begin{array}{l}\text { Universida } \\
\text { de Federal } \\
\text { de Juiz de } \\
\text { Fora }\end{array}$ & $\begin{array}{l}\text { Programa de } \\
\text { Pós- } \\
\text { Graduação } \\
\text { Em Educação }\end{array}$ & $\begin{array}{l}\text { Ações Formativas } \\
\text { (Institucionais) para a Docência } \\
\text { no Ensino Superior nas } \\
\text { Universidades Públicas Federais } \\
\text { Brasileiras }\end{array}$ & 2019 & $\mathrm{~T}$ \\
\hline $\begin{array}{l}\text { Kaline } \\
\text { Valeria } \\
\text { Pereira Silva }\end{array}$ & $\begin{array}{l}\text { Universida } \\
\text { de Federal } \\
\text { de } \\
\text { Pernambuc } \\
\text { o }\end{array}$ & $\begin{array}{l}\text { Programa de } \\
\text { Pós- } \\
\text { Graduação } \\
\text { Em Educação }\end{array}$ & $\begin{array}{l}\text { Contributos do Nufope no } \\
\text { Processo de Reconfiguração de } \\
\text { um Lugar para a Formação } \\
\text { Didático-Pedagógica }\end{array}$ & 2014 & $\mathrm{D}$ \\
\hline $\begin{array}{l}\text { Maria } \\
\text { Consolador } \\
\text { a Parisotto } \\
\text { Oro }\end{array}$ & $\begin{array}{l}\text { Universida } \\
\text { de Estadual } \\
\text { do Oeste } \\
\text { do Paraná - } \\
\text { Unioesc }\end{array}$ & $\begin{array}{l}\text { Programa de } \\
\text { Pós- } \\
\text { Graduação } \\
\text { Em Educação }\end{array}$ & $\begin{array}{lrr}\text { A Docência } & \text { Universitária e a } \\
\text { Importância } & \text { do } & \text { Apoio } \\
\text { Institucional a } & \text { Formação } \\
\text { Pedagógica dos } & \text { Professores } \\
\text { Bacharéis: } \text { o } & \text { caso da } \\
\text { Unioeste/Campus Cascavel-PR }\end{array}$ & 2012 & $\mathrm{D}$ \\
\hline $\begin{array}{l}\text { Maria Lucia } \\
\text { Marocco } \\
\text { Maraschin }\end{array}$ & $\begin{array}{l}\text { Universida } \\
\text { de } \text { Federal } \\
\text { do Rio } \\
\text { Grande do } \\
\text { Sul }\end{array}$ & $\begin{array}{l}\text { Programa de } \\
\text { Pós- } \\
\text { Graduação em } \\
\text { Educação }\end{array}$ & $\begin{array}{l}\text { Formação Continuada do } \\
\text { Professor da Educação Superior } \\
\text { Promovida por Ações } \\
\text { Institucionais }\end{array}$ & 2012 & $\mathrm{D}$ \\
\hline $\begin{array}{l}\text { Rejane } \\
\text { Bezerra } \\
\text { Barros }\end{array}$ & $\begin{array}{l}\text { Universida } \\
\text { de } \\
\text { do }\end{array}$ & $\begin{array}{l}\text { Programa de } \\
\text { Pós- }\end{array}$ & 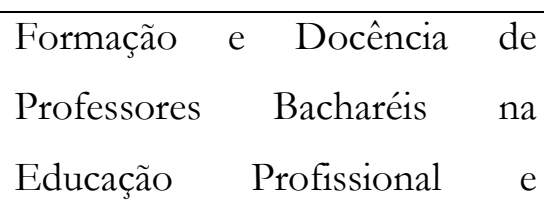 & 2016 & $\mathrm{~T}$ \\
\hline
\end{tabular}




\begin{tabular}{|c|c|c|c|c|c|}
\hline & $\begin{array}{l}\text { Grande do } \\
\text { Norte }\end{array}$ & $\begin{array}{l}\text { Graduação em } \\
\text { Educação }\end{array}$ & $\begin{array}{l}\text { Tecnológica no IFRN: uma } \\
\text { interface } \\
\text { emancipatória. }\end{array}$ & & \\
\hline $\begin{array}{l}\text { Renata de } \\
\text { Souza } \\
\text { Martinez }\end{array}$ & $\begin{array}{l}\text { Universida } \\
\text { de Estadual } \\
\text { Paulista }\end{array}$ & $\begin{array}{lr}\text { Programa } & \text { de } \\
\text { Educação } & \\
\text { Escolar } & \text { da } \\
\text { Faculdade de } & \text { diências } \\
\text { Letras } & \text { e }\end{array}$ & $\begin{array}{l}\text { Ações Organizacionais } \mathrm{e} \\
\text { Formação Continuada para } \\
\text { Ação Docente no Ensino } \\
\text { Superior. }\end{array}$ & 2019 & $\mathrm{~T}$ \\
\hline $\begin{array}{l}\text { Sueli Petry } \\
\text { da Luz }\end{array}$ & $\begin{array}{l}\text { Universida } \\
\text { de Estadual } \\
\text { de } \\
\text { Campinas }\end{array}$ & $\begin{array}{l}\text { Faculdade de } \\
\text { Educação }\end{array}$ & $\begin{array}{l}\text { Formação Continuada para } \\
\text { Docentes da Educação Superior: } \\
\text { um estudo de caso }\end{array}$ & 2007 & $\mathrm{~T}$ \\
\hline
\end{tabular}

Fonte: Elaborado pelas autoras com base nos dados da BDTD (2020).

Reforça-se que o objetivo desse artigo é apresentar o que tem sido discutido no âmbito das pesquisas realizadas no Brasil no que diz respeito à formação continuada do professor na Educação Superior. Mesmo que o critério estabelecido atenda uma parte do que tem sido estudado, o que é uma limitação desse estudo, permite que se tenha uma visão das perspectivas adotadas pelos pesquisadores. E também sirva para futuras pesquisas na área com esse tema. No próximo tópico apresentar-se-á o que tem sido pesquisado e a análise baseada em autores que discutem o tema.

\section{A FORMAÇÃO CONTINUADA}

A formação continuada de professores é um caminho para garantir a constituição docente, contudo é notória a preocupação com os objetivos e a qualidade de tais atividades. Nóvoa (1999), faz pensar que novos "cursos" de formação continuada não serão produtivos se não forem realmente planejados para oportunizar aos professores que busquem subsídios que os permitam integrar as dimensões cotidianas da profissão, tornando-as parte essencial da definição de cada um como professor.

E nesse sentido ele afirma,

É impossível falar de uma mudança que não passe pela formação de professores. Não estou a falar de mais um programa de formação a juntar com tantos outros que todos os dias são lançados. Quero dizer, sim, da necessidade de uma outra concepção, que 
situe o desenvolvimento pessoal e profissional dos professores ao longo dos diferentes ciclos da sua vida (NÓVOA, 1999).

Assim, é preciso considerar na formação docente, de um lado, uma formação cultural básica que contribua para a compreensão do ensino e educação, e de outro, formação em conhecimento e compreensão do sistema escolar e da escola como espaço sociocultural com especificidades (GATTI, 2016).

Os 10 trabalhos analisados foram divididos em dois grandes grupos: as pesquisas que tiveram como universo os seus programas de formação continuada e as que investigaram as percepções sobre a formação continuada tendo o olhar voltado para as opiniões de professores e gestores da própria instituição.

No primeiro grupo de pesquisa, percepções sobre a formação continuada desenvolvida na instituição, quatro trabalhos foram identificados. O estudo de Sousa (2013), Judilma Silva (2019), Kaline Silva (2014) e Luz (2007) reforçam os aspectos apresentados por Nóvoa (1999) e Gatti (2016). Sousa (2013) objetivou compreender implicações da formação continuada na (re)construção da identidade profissional docente de professores universitários, a partir da identificação do processo de formação continuada que está sendo realizado na Educação Superior, e da identificação dos elementos que possibilitam o reconhecimento dessa formação na construção da identidade profissional docente.

Os pesquisados trouxeram como se sentiam como docentes o que revelou que a prática profissional ao longo dos anos trouxe segurança no exercício da docência. Sobre a formação continuada pode-se listar alguns achados da pesquisa: os docentes puderam refletir sobre suas ações em sala de aula; promoveu mudanças em sua prática docente; melhor conhecimento da organização e das diversas áreas de conhecimento que compõem a universidade; ajudou no processo de formação profissional e pessoal dos docentes envolvidos (SOUSA, 2013).

A análise de Judilma Silva (2019) buscou investigar se as Instituições de Educação Superior federais têm desenvolvido ações institucionais voltadas à formação docente e de que forma a cultura digital está inserida nesse processo. Como resultado aponta para um crescimento das ações com opções variadas além de boas possibilidades de incorporação das tecnologias.

O estudo de Kaline Silva (2014) teve como objetivo caracterizar as contribuições do Núcleo de Formação Continuada Didático-Pedagógica de Professores da UFPE (NUFOPE) como ferramenta no desenvolvimento docente. Através da pesquisa, a autora identificou que o envolvimento com uma formação didático-pedagógica de forma continuada é resultado de construções pessoais-profissionais. 
A pesquisa de Luz (2007) apresenta alguns pontos que vão ao encontro do que os autores defendem. Ela analisou um Programa de Formação Continuada para os docentes da Educação Superior da Univali que aconteceu no período de 2000 a 2004 para investigar a opinião dos professores e gestores sobre as mudanças na prática docente em sala de aula que pudessem ser atribuídas ao programa através de entrevistas e questionários. O resultado trouxe que apesar da instituição proporcionar no calendário letivo datas para a formação, ser discutido temas relevantes para a docência, os professores não participaram da organização do programa e os temas foram escolhidos sem levarem em relação as áreas específicas de atuação dos professores que participaram da formação.

Também nessa tese, Luz (2007) encontrou em seus achados algo que Cunha (2014) defende: a interlocução com seus pares. A interação entre os espaços de trabalho e de aprendizagem num contexto interpessoal contribui para a qualidade da formação. Não há mais espaço para se olhar para a formação continuada como responsabilidade individual e um processo solitário, visto que, as aprendizagens acontecem quando há uma cultura institucional que as estimule e valorize. Assim, chama-se as instituições para pensar a formação continuada por outro viés (CUNHA, 2014).

A valorização das experiências do professor com seus alunos, constitui um campo preferencial de formação e teorização das práticas pedagógicas da educação. A socialização dessas experiências além de fortalecer a valorização do trabalho, permite que se possa refletir, avaliar e ponderar avanços e desafios, bem como interromper a tradição de que a tarefa docente é individual e autônoma. Passa-se a construir comunidades docentes de aprendizagem, onde o que um professor vive, pode servir para o outro, fortalecendo o conhecimento dinâmico (CUNHA, 2014). Neste contexto de troca de experiências e compartilhamento de ideias, torna-se importante conhecer o que os professores pensam a respeito da formação continuada da qual participam.

O segundo grupo de trabalhos identificados é o referente as percepções dos professores sobre a formação continuada. Nesse grupo encontra-se seis trabalhos: Blanco (2017), Martinez (2019), Paz (2010), Barros (2016), Oro (2012) e Maraschini (2012). A pesquisa de Blanco (2017) abordar um olhar sobre a formação de professores para a disciplina de história e trouxe algumas respostas que se aproximam do que tem sido defendido por Pimenta (2002), Gil (2007) e Contreras (2002). A autora buscou respostas através de revisão bibliográfica e entrevistas semi-estruturadas, questionando aos participantes o que os levou a serem docentes e o que motivou a escolha do seu curso, quais saberes possuem e como buscam se aprimorarem através da formação continuada. Como resultados, obteve apontamentos por parte dos docentes sobre grandes lacunas deixadas em sua formação inicial e uma grande distância entre o que se aprende e a realidade escolar e ainda, houve o apontamento por parte dos docentes sobre "uma maior preocupação em responsabilizar 
os 'culpados' pelo insucesso da educação do que uma formação voltada à preparação do docente para lidar com os problemas que lhes são impostos, cotidianamente, pela prática” (BLANCO, 2017, p. 116).

Uma pesquisa que trouxe a reflexão sobre as ações organizacionais e formação continuada para ação docente foi a de Martinez (2019). Teve como tese que o docente sendo profissional da Educação Superior tem necessidade de capacitação e aprimoramento permanente para seu fazer enquanto professor. O seu resultado é coerente com o que foi discutido pelos vários autores nos tópicos anteriores. Mas aponta para um dificultador, a rotatividade dos professores. Os “[...] resultados eficazes são possíveis através das ações organizacionais voltadas para a formação continuada docente, desde que se mantenham a permanência do mesmo grupo de professores e a frequência dos encontros de formação”. (MARTINEZ, 2019, p. 68).

Já a pesquisa de Paz (2010) traz algumas aproximações com as ideias de Gil (2007) e as de Tardif (2015) quando promove uma reflexão sobre a formação de professores para a Educação Superior, mais especificamente do Programa de Profissionalização Pedagógica Continuada dos Professores da Unisul de 2004 a 2009. Como um dos resultados, ressalta-se que não basta conhecer o que irá ensinar (conteúdo específico) porque o saber pedagógico ocorrerá naturalmente, é necessário também buscar alternativas a esse saber, uma vez que, segundo o autor "a competência do professor está vinculada a sua capacidade de lidar com os saberes (cognitivos, procedimentais e atitudinais), bem como a habilidade e a sensibilidade para construí-los e reconstruí-los". O autor ainda ressalta que a docência resulta da composição de titulação e saberes pedagógicos resultantes de uma boa formação continuada que deve ser de responsabilidade da Instituição de Educação Superior e um compromisso do docente.

Essa formação continuada sob a responsabilidade da Instituição de Educação Superior, principalmente para os professores que têm uma formação mais técnica, foi tema de outros estudos analisados, como o de Barros (2016) que pesquisou a formação dos professores bacharéis que trabalham na Educação Profissional e Tecnológica no Instituto Federal do Rio Grande do Norte. Um dos resultados encontrados é que

[...] os professores inquiridos por meio de questionários e os gestores entrevistados reconhecem a necessidade de a instituição investir em processos formativos no lócus do trabalho, na perspectiva da formação continuada, de forma permanente, em cursos de formação e atualização pedagógica, para os professores da instituição. (BARROS, 2016, p. 64).

Nesse sentido, a pesquisadora elaborou em sua tese uma proposta para a formação continuada permanente dos professores que chamou de Programa de Formação e Atuação 
Docente que seria apresentada para possível implementação na instituição. Foi o único trabalho analisado que apresentou uma proposta concreta para o resultado das demandas levantadas pelos gestores e professores. Sobre esse aspecto podem ser citados alguns autores que discutem a formação continuada.

Malglaive (1997) afirma que é preciso se quebrar a compreensão de que a formação continuada é um prolongamento da formação inicial, com forte vínculo à tradição acadêmica e que raramente inclui os saberes contextuais da prática. Neste sentido, Nóvoa (1999) expõe que cada vez mais se preconiza uma formação que regresse aos espaços de trabalho e os tenha como referente das ações formativas. O que a pesquisa de Barros (2016) mostrou enquanto necessidade.

Também autores como Alvarado-Prada, Freitas e Freitas (2010) trazem os tipos de formação continuada que são oferecidos aos professores, dentre eles surgem palestras, cursos de 10 ou 15 horas, oficinas, seminários, ou seja, atividades pontuais sem continuidade ao longo dos meses e anos escolares. Muitas vezes, o entendimento dos professores acerca da formação continuada é de que a mesma é muito importante, contudo não gostam da imposição com que elas são apresentadas, sendo que das atividades que mais gostam estão as oficinas e discussão de práticas de sala de aula.

Oro (2012) através da pesquisa qualitativa com professores bacharéis de 12 cursos de graduação da UNIOESTE/Campus Cascavel/PR teve como objetivo conhecer as condições pedagógicas no exercício da ação docente na universidade, para aqueles docentes que advêm de cursos de bacharelado, partindo da hipótese de que esse professor, na maioria das vezes, não traz em sua formação o conhecimento necessário para o fazer pedagógico, indispensável para o correto exercício da docência.

Os resultados encontrados confirmam essa hipótese, tanto no aspecto bibliográfico quanto de campo. Observou-se uma inclinação dos docentes à pesquisa o que exige mais conhecimento específico e menos dedicação à didática pedagógica, e que os programas de mestrado e doutorado apesar de aproximar à profissão docente, não se preocupam com os saberes próprios da docência. De acordo com os respondentes, além de não encontrarem formação pedagógica nos programas stricto sensu, não encontram consistentes programas institucionalizados de educação continuada que lhes proporcionem os conhecimentos teóricos e práticos da profissão que abraçaram. É imprescindível que a universidade se reposicione em relação à formação continuada de professores dada sua importância e também tenha novo olhar para a formação dos programas de Mestrado e Doutorado nessa mesma direção.

O trabalho de Maraschini (2012) teve como objetivo identificar e analisar as práticas e políticas de formação continuada concebidas e promovidas pelas Universidades Comunitárias 
Catarinenses, com destaque para as concepções e significados atribuídos pelos professores às ações promovidas institucionalmente. Desenvolveu o estudo qualitativo e exploratório a partir da análise de documentos oficiais: Plano de Desenvolvimento Institucional, Projeto Político Institucional e Política de Formação Continuada, além de entrevistas com gestores, coordenadores e professores. Como resultados o estudo traz a avaliação institucional como ferramenta orientadora da formação continuada; os programas de formação continuada desenvolvidos buscam atender a demandas gerais e específicas da comunidade acadêmica; inicialmente a formação continuada acontecia no formato de eventos isolados e agora seguem em formato de programas contínuos; há um interesse grande das instituições pesquisadas em desenvolver com qualidade a formação de professores como estratégia para a qualidade de ensino e permanência dos estudantes.

Dos trabalhos analisados emergem alguns aspectos que merecem atenção:

- o professor precisa ter uma formação que permita que ele entenda os processos que estão envolvidos no ensinar;

- ter uma formação de uma área específica de conhecimento pode prejudicar no exercício pleno da profissão docente;

- a formação continuada pode ajudar o professor a se constituir enquanto professor na Educação Superior;

- as instituições têm proporcionado alguns programas de formação continuada, mas alguns não atendem às reais necessidades dos professores;

- as pesquisas analisadas, em sua grande parte tem tido como objetivo avaliar programas existentes e/ou levantar as percepções dos professores sobre formação continuada, mas são incipientes quando diz respeito à propostas concretas de formação continuada com base nos resultados de pesquisa encontrados.

No próximo tópico apresenta-se as considerações gerais a título de finalização do artigo, mas como um convite para se continuar a pesquisar sobre o tema e aprofundar nas discussões que foram incitadas pelos resultados das pesquisas analisadas.

\section{CONSIDERAÇÕES FINAIS}

Como constatado o objetivo proposto neste artigo foi alcançado ao apresentar o que tem sido pesquisado sobre a formação continuada de professores da Educação Superior. O resultado da análise permitiu agrupar as pesquisas em dois grandes grupos: análise de programas de formação continuada ofertados aos professores da Educação Superior pelas instituições que foram o lócus de 
pesquisa e as percepções dos professores sobre a sua formação e a importância da formação continuada.

Alguns aspectos chamam à atenção: poucos foram as formações oferecidas pelas instituições a nível de formação continuada que tiveram como critério de implementação ouvir e planejar com os professores para atender a sua real necessidade. A grande incidência de programas que foram oferecidos trouxe em suas motivações atenderem a uma demanda percebida e gerenciada totalmente pelos gestores das instituições.

Uma outra questão também chama a atenção, a grande incidência de pesquisas que foram para conhecer uma determinada realidade ou percepções, sem trazer um indicativo em suas considerações de como as informações poderiam ser utilizadas para mudar a realidade vivenciada pela instituição e/ou professor, como a pesquisa já foi realizada por Barros (2016) que trouxe ao final uma proposta que atenderia aos resultados que foram sendo construídos com os professores e gestores.

Também ficou evidente que há uma incidência maior de pesquisas em programas de educação sobre a formação continuada para professores da Educação Superior, apesar de ter como um dos pontos fortes para a proposta da formação continuada atender a todas as áreas de conhecimento. Houve trabalhos específicos com os bacharéis que deixaram claro a necessidade da formação continuada oferecida pelas próprias instituições que atuam, mas levando em conta as suas especificidades.

De forma geral, tem-se a impressão que essa área é um tema emergente que precisa ser melhor explorado enquanto pesquisa e também enquanto necessidade nas próprias instituições de Educação Superior no país de forma prospectiva e não somente retrospectiva com vem sendo estudada.

\section{REFERÊNCIAS}

ALVARADO-PRADA, Luis Eduardo; FREITAS, Thaís Campos; FREITAS, Cinara Aline. Formação continuada de Professores: alguns conceitos, interesses, necessidades e propostas. Rev. Diálogo Educ., v. 10, n. 30, p. 367-387, 2010. DOI: http://dx.doi.org/10.7213/rde.v10i30.2464. Disponível em: https://periodicos.pucpr.br/index.php/dialogoeducacional/article/view/2464. Acesso em: ago. 2020.

BARROS, Rejane Bezerra. Formação e docência de Professores bacharéis na educação profissional e tecnológica no IFRN: uma interface dialógica emancipatória. 2016. 337f. Tese (Doutorado) - Programa de Pós-Graduação em Educação, Universidade Federal do Rio Grande do Norte, Natal/RN, 2016. 
BLANCO, Fernanda de Melo. Saberes da docência: um estudo sobre a formação de professores de História. 2017. 121 f. Dissertação (Mestrado em Planejamento e Análise de Políticas Públicas) Faculdade de Ciências Humanas e Sociais, Universidade Estadual Paulista "Júlio de Mesquita Filho", Franca, 2017.

BRASIL. Instituto Nacional de Estudos e Pesquisas Educacionais Anísio Teixeira.

Instrumento de Avaliação dos Cursos de Graduação Presencial e a Distância. 2016. Disponível em: <http://portal.inep.gov.br/superior-condicoesdeensino-manuais>. Acesso em: out. 2018.

Lei $\mathrm{n}^{\circ}$ 9394, de 20 de dezembro de 1996. Estabelece as diretrizes e bases da educação nacional. Disponível em: http://www.planalto.gov.br/ccivil_03/Leis/L9394.htm. Acesso em: out. 2018.

CONTRERAS, José. A autonomia de professores. São Paulo: Cortez, 2002,

CUNHA, Maria Isabel da. Aprendizagem da docência em espaços institucionais: é possível fazer avançar o campo da formação de professores? Avaliação, v. 19, n. 3, p. 789-802, 2014. https://doi.org/10.1590/S1414-40772014000300013. Disponível em: https://www.scielo.br/scielo.php?script=sci_arttext\&pid=S1414-40772014000300013. Acesso em: ago. 2020.

DIEHL, Astor Antônio e TATIM, Denise Carvalho. Pesquisa em ciências sociais aplicadas. São Paulo: Prentice Hall, 2004.

FELICETTI, Vera Lucia; SANTOS, Bettina Steren dos. Estudante da Educação Superior em contextos emergentes. In: FRANCO, Sérgio Roberto Kieling; FRANCO, Maria Estela Dal Pai; LEITE, Denise Balarine Cavalheiro (orgs). Educação Superior e conhecimento no centenário da Reforma de Córdoba: novos olhares em contextos emergentes. Porto Alegre: EDIPUCRS, 2019. Cap. V, p. 211-225.

FREIRE, Paulo. Professora sim, tia não. Cartas a quem ousa ensinar. São Paulo: Olho d'água, 1995.

Paulo. Pedagogia da Autonomia. São Paulo: Paz e Terra, 2015

GATTI, Bernardete A. Formação de professores: condições e problemas. Revista Internacional de Formação de Professores, v. 1, n. 2, 2016. Disponível em: https://periodicos.itp.ifsp.edu.br/index.php/RIFP/article/view/347. Acesso em: ago. 2020.

GIL, Antonio Carlos. Metodologia do Ensino Superior. 4. ed. São Paulo: Atlas, 2007.

LEITE, Denise (Org.). Pedagogia universitária: conhecimento, ética e política no ensino superior. Porto Alegre: Universidade-UFRGS, 1999.

LUZ, Sueli Petry da. Formação Continuada para Docentes da Educação Superior: um estudo de Caso. 2007. 244 p. Tese (Doutorado em Educação) - Universidade Estadual de Campinas, Campinas, 2007. 
MALGLAIVE, Gerard. Formação e saberes profissionais: entre a teoria e a prática. In: (CANARIO, R. (Org.)). Formação e situações de trabalho. Porto: Porto Editora, 1997. p. 5360.

MARTINEZ, Renata de Souza. Ações organizacionais e formação continuada para ação docente no Ensino Superior. 2019. 98f. Tese (Doutorado) - Programa de Educação Escolar da Faculdade de Ciências e Letras, Universidade Estadual Paulista "Júlio de Mesquita Filho", Faculdade de Ciências e Letras, Araraquara/SP, 2019.

MARASCHIN, Maria Lucia Marocco. Formação Continuada do Professor da Educação Superior Promovida por Ações Institucionais. 2012. 211f. Dissertação (Mestrado) - Programa de Pós-Graduação em Educação. Universidade Federal do Rio Grande do Sul, Porto Alegre, 2012.

MASETTO, Marcos T. Competência pedagógica do professor universitário. 9. ed. São Paulo: Summus, 2008.

MOROSINI, Marília Costa. Qualidade da Educação Superior e contextos emergentes. Avaliação, Campinas [online], v. 19, n. 2, p. 385-405, 2014. DOI: https://doi.org/10.1590/S1414$40772014000200007 . \quad$ Disponível em: https://www.scielo.br/scielo.php?script=sci_arttext\&pid=S141440772014000200007\&lng=en\&nrm=iso\&tlng=pt. Acesso em: 20 ago. 2020.

NÓVOA, Antonio. La nueva cuestión central de los profesores: exceso de discursos, pobreza de prácticas. Cuadernos de Pedagogía, n. 286, p. 102-108, 1999.

ORO, Maria Consoladora Parisotto. A docência universitária e a importância do apoio institucional à formação pedagógica dos professores bacharéis: o caso da UNIOESTE Campus Cascavel-PR. 2012.95f. Dissertação (Mestrado em Educação) - Programa de PósGraduação Stricto Sensu em Educação. Universidade Estadual do Oeste do Paraná UNIOESTE. Cascavel, 2012.

PAZ, Cláudio Damaceno. O desafio da formação de professores para a Educação Superior: o programa de profissionalização pedagógica continuada dos professores da UNISUL (2004-2009). 2010. 160 f. Dissertação (Mestrado em Educação) - Programa de Pós-Graduação em Educação, Universidade do Sul de Santa Catarina, Santa Catarina, 2010.

PERRENOUD, Philippe. Avaliação: da excelência à regulação das aprendizagens - entre duas lógicas. Porto Alegre: Artmed, 1999.

PIMENTA, Selma Garrido. Professor: formação, identidade e trabalho docente. In: PIMENTA, Selma Garrido. (Org.). Saberes pedagógicos e atividade docente. 3. ed. São Paulo: Cortez, 2002. p. 15-34.

ANASTASIOU, Léa das Graças Camargos. Docência no Ensino

Superior. 2. ed. São Paulo: Cortez, 2005.

SILVA, Judilma Aline Oliveira. Ações formativas (Institucionais) para a docência no Ensino Superior nas Universidades Públicas Federais Brasileiras. 2019. 554f. Tese (Doutorado em Educação) - Programa de Pós-graduação em Educação, Universidade Federal de Juíz de Fora. Juíz de Fora, 2019 
SILVA, Kaline V. Pereira. Contributos do NUFOPE no Processo de Reconfiguração de um Lugar para a Formação Didático-Pedagógica. 2014. 146 p. Dissertação (Mestrado em Educação) - Universidade Federal de Pernambuco, 2014.

SOUSA, Gabrielle Barbosa de. Formação Continuada de Professores do Ensino Superior: Composição Organizativa da Identidade Docente. 2013. 154f. Dissertação (Mestrado) - Programa de Pós-Graduação em Educação. Universidade Federal de Pernambuco, Recife, 2013.

TARDIF, Maurice. Saberes docentes e formação profissional. 14. ed. Petrópolis: Vozes, 2015. 